\title{
Ultrarapid opiate detoxification: a review
}

\author{
[Désintoxication opiacée ultrarapide : une revue]
}

Alan D. Kaye MD PhD, ${ }^{*}$ Clifford Gevirtz MD,$\dagger$ Hemmo A. Bosscher MD, $\ddagger$ Joe B. Duke MED $\ddagger$ Elizabeth A.M. Frost MD, $\dagger$ Todd A. Richards MD, $\ddagger$ Aaron M. Fields MD $\ddagger$

Purpose: This review on ultrarapid detoxification examines the pharmacology, techniques, and efficacy of this potentially promising technique and contrasts it with conventional treatment modalities.

Source: The information found here is derived from experiences at the Texas Tech University, government reports, and peer reviewed journals.

Principal findings: Incidence and prevalence of heroin use is on the rise. Social and treatment costs suggest that this problem is staggering. Approximately 400,000 patients are enrolled in or are actively seeking methadone therapy. While many of these individuals want to undergo detoxification, traditional techniques, including methadone tapering are usually unsuccessful. The withdrawal syndrome is extremely unpleasant, may be fatal, and deters patients from completing the detoxification process. Ultrarapid detoxification entails general anesthesia in conjunction with large boluses of narcotic antagonists. This combination allows the individual to completely withdraw from the opiate without suffering the discomfort of the withdrawal syndrome. Unless performed properly, this procedure can be dangerous due to the sympathetic outflow. However, with proper support, this danger can be mitigated.

Conclusion: Ultrarapid opiate detoxification, performed under the proper circumstances, is associated with few adverse events and is relatively comfortable for patients who seek treatment for their addition.

Objectif : La présente étude portant sur la désintoxication ultrarapide revoit la pharmacologie, les techniques et l'efficacité de cette technique potentiellement prometteuse et la compare avec les modalités thérapeutiques traditionnelles.

Source : Nos informations sont tirées des expériences à la Texas Tech University, des rapports officiels et des journaux scientifiques.

Constatations principales : L'incidence et la prévalence de l'usage d'héroïne sont en hausse. Les coûts sociaux et thérapeutiques de ce problème sont renversants. Environ 400000 patients suivent, ou cherchent activement, un traitement à la méthadone. Beaucoup acceptent une désintoxication, mais les techniques traditionnelles, incluant l'approche dégressive avec la méthadone, sont habituellement infructueuses. Le syndrome de sevrage est très désagréable, peut être fatal et décourage les patients d'aller jusqu'au bout. La désintoxication ultrarapide nécessite une anesthésie générale conjointement avec d'importants bolus d'antagonistes narcotiques. Cette combinaison permet la suppression complète des opiacés sans subir l'inconfort du syndrome de sevrage. Si elle n'est pas réalisée correctement, cette intervention comporte un danger, lié à l'influx sympathique, danger réduit par une assistance appropriée.

Conclusion : La désintoxication ultrarapide aux opiacés, réalisée dans des conditions appropriées, est associée à peu d'événements indésirables et est relativement confortable pour les patients qui cherchent un traitement à leur dépendance.

\section{Overview}

Incidence and prevalence of heroin use is on the rise. ${ }^{1,2}$ Social and treatment costs suggest this problem is staggering. Consequently, definition and treatment of opiate addiction and dependency has become a focus for professionals such as social workers, psychologists, psychiatrists, and law enforcement officers many of whom exhibit laudable intentions but a paucity of scientific knowledge about the phenomena of tolerance and dependence.

Opiate dependence can be viewed as a physical illness or a central nervous system disorder resulting from chronic opiate intake. After long-term use of opiates, the nerve cells, normally producing endogenous opiates, cease to function and degenerate causing the user to become physically dependent on exogenous opiates. Sudden opiate abstinence induces a trau-

From the Departments of Anesthesiology $\ddagger$ and Pharmacology, $\ddagger$ Texas Tech University School of Medicine, Lubbock, Texas; and the Department of Anesthesiology, $†$ Mount Sinai School of Medicine, New York, New York, USA.

Address correspondence to: Dr. Alan D. Kaye, Department of Anesthesiology, Room 1C-282, 3601 4th Street STOP 8182, Lubbock,

TX 79430-8182, USA. Phone: 806-743-4176; Fax: 806-743-2982; E-mail: alan.kaye@ttuhsc.edu

Reviewed September 30, 2002.

lst revision January 14, 2003.

2nd revision accepted March 19, 2003. 
matic disorder, the withdrawal syndrome, possibly leading to permanent damage to the cardiopulmonary and/or central nervous systems.

Traditionally, opiate addicts seeking medical care for addiction have undergone conventional detoxification procedures that required individuals to suffer through the withdrawal syndrome. More recent efforts have been aimed at substituting methadone for the illicit drugs in an effort to "cure" the addiction.

Estimates in 1999 state that about 14.8 million Americans were current users of illicit drugs. Community Epidemiology Work Group (CEWG) members identified several legal prescription drugs as emerging drugs of abuse in 1999. These include clonazepam (a benzodiazepine) and the controlled substances hydrocodone (Lorcet ${ }^{\circledR}, \quad$ Lortab $\AA, \quad$ Vicodin $\left.{ }^{\circledR}\right)$, hydromorphone (Dilaudid $\left.{ }^{\circledR}\right)$, and oxycodone (Percodan ${ }^{\circledR}$, Percocet ${ }^{\circledR}$ ). From 1993 to 1999, hydrocodone associated emergency room visits increased from 6,115 to $14,639 .{ }^{1}$ Between 1994 and 1995, there was a 19\% increase in heroin-related emergency department visits. ${ }^{3}$ According to the 1998 National Household Survey on Drug Abuse, an estimated 2.4 million people had used heroin at some time in their lives, and nearly 130,000 of them reported using it within the month preceding the survey. ${ }^{4}$

Given the rapid increase in the number of opiate users, present measures including psychological counselling, pharmacological intervention, and inpatient detoxification are proving inadequate. A comprehensive approach that addresses both the medical and psychological components of opiate addiction is needed.

\section{Opioid pharmacology as it relates to addiction}

When opiate receptors were first discovered, they were thought to be found exclusively in the central nervous system. These central effects include respiratory depression, convulsions, miosis, and suppression of the cough reflex. More recent research has shown these receptors to be found in virtually all organ systems including the gastrointestinal tract, the kidneys, the liver, and the sympathetic ganglia. The endogenous opioid systems have also been shown to play a role in the regulation of cardiovascular functions.

Since the morphine antagonist naloxone can increase pain, it appears that release of $\beta$-endorphin and/or other endogenous opioids may modulate the perception of pain. It also is clear that endogenous opioids have other physiological properties. For example, they can affect respiration, vasopressin release, and free water clearance by the kidneys. Recently, these compounds have been implicated in the pathogenesis of hypertension, hemorrhagic shock, and additional stress states including sepsis. ß-endorphin increases during increased stress conditions such as surgery, pregnancy, labour and delivery, insulin-induced hypoglycemia, the administration of vasopressin, and post-adrenalectomy or following administration of metyrapone.

Recent research has shown that down regulation of opioid receptors takes place when high levels of agonists are present for long periods of time. This down regulation is both receptor-density dependent and receptor-density independent. ${ }^{5}$ This down regulation and the ubiquitous distribution of peripheral opiate receptors could explain the wide range of symptoms experienced by the patient with withdrawal symptoms.

When used regularly, heroin and other opiates result in physical dependence or neuroadaptation. In addition to other systemic receptors, opiates act on receptor sites within the brain. People who become dependent on exogenous opiates can be treated pharmacologically using either agonist or antagonist drugs. Agonists, such as methadone, meet the need of the neurons for external opiates. Naltrexone, an opiate antagonist, blocks the opiate receptor, blunting the euphoric effects and cravings for opiates. Neuroadaptation of the central nervous system due to exogenous opiates may be returned to pre-addiction levels with the use of naltrexone or other antagonists. ${ }^{6}$

Understanding the neurochemical processes in the development of drug addiction will provide a foundation for the development of pharmacological treatments for this disease. ${ }^{1}$ Drug addiction can be defined as a chronic, relapsing brain disorder characterized by neurobiological changes leading to compulsive drug taking behaviours.

Adaptive changes at the cellular level compensate for the continued inhibitory effects of the opiate..$^{7-9}$ Presence of an opiate becomes a requirement for normal functioning of the cell. This dependency is associated with alterations in several components of the cyclic adenosine monophosphate (cAMP) signal transducer cascade. The transcription factor, cAMP response element binding protein (CREB), is altered in response to chronic opiate exposure. ${ }^{10-12}$ Symptoms of withdrawal have been demonstrated in CREB knockout mice. ${ }^{13}$ Chronic receptor stimulation causes compensatory increases in adenylate cyclase activity, leading to elevations in cellular cAMP levels. This induces phosphodiesterase activity, increasing cAMP degradation to maintain homeostasis. Lack of receptor inhibition by an antagonist may result in a compensatory response, resulting in a sudden increase in cAMP concentration. This sequence of events may be responsible for the pathophysiological changes seen in the withdrawal syndrome. ${ }^{14}$ Chronic exposure to opi- 
oids may also be associated with changes to the $\mu$ receptor resulting in the propagation of signal transduction in the absence of an agonist. ${ }^{15}$ Due to cellular changes that must take place after long-term opiate exposure, the withdrawal phase can be protracted, and it may take months for subjects to be symptom free. ${ }^{1}$

\section{Detoxification/withdrawal}

A variety of methods have been utilized for the treatment of opioid withdrawal before patients begin longterm opioid free and naltrexone programs. Most widely accepted is a slow supervised detoxification process in which methadone is substituted for the abused opiate. Methadone merely replaces one opiate for another. However, it can improve general and psychological health, and social functioning. In addition, it can decrease illicit drug use, criminal activity, and the risk of contracting infectious disease. Once the patient is stabilized on a methadone maintenance program, the drug is slowly tapered in such a way that withdrawal and risks of complications are minimized.

Methadone is highly bound to plasma proteins, and it accumulates more than heroin in all body tissues. It also has a longer half-life which is about $22 \mathrm{hr} .{ }^{16}$ This can make withdrawal from methadone more difficult than from heroin. Substitution therapy with methadone has a high initial dropout rate (30-90\%) and an early relapse rate. ${ }^{17-19}$ Alternative pharmacological detoxification programs include the use of clonidine with or without methadone, midazolam, trazadone or buprenorphine. ${ }^{20}$ Non-pharmacological programs using cranial stimulation or more rigorous methods have reported varied success rates. ${ }^{21,22}$

\section{The role of $a_{2}$-agonists}

Symptoms associated with the withdrawal syndrome, such as restlessness, rhinorrhea, lacrimation, diaphoresis, myosis, piloerection, and cardiovascular changes are mediated through increased sympathetic activity. Thirtyfold increases in the levels of epinephrine and lesser increases in norepinephrine can be observed during withdrawal from opioids. ${ }^{23}$

During opioid withdrawal, neural activity in the locus ceruleus, the major noradrenergic nucleus in the brain, is greatly increased. This surge is responsible for many of the symptoms seen during withdrawal. ${ }^{24,25}$ Clonidine, an $\mathrm{a}_{2}$-agonist, has been shown effective in suppressing noradrenergic hyperactivity, relieving withdrawal symptoms. ${ }^{26-28}$

\section{The role of opioid antagonists}

Opioid antagonists, such as naloxone, naltrexone, or nalmefene accelerate the process of detoxification.
These substances bind the opioid receptor and block these sites from interacting with the agonists. Once opiate antagonism is established, if an opiate is consumed, it will have no effect. ${ }^{29}$

Using a rapid detoxification protocol allows a more rapid introduction of opioid antagonist maintenance therapy with a subsequent reduction in relapse rates. ${ }^{30}$ The acute short-lasting opioid withdrawal syndrome can be more severe than that associated with a more conventional withdrawal. These symptoms are very rarely life threatening but are sufficiently adverse and act as a major deterrent to addicts who want to cease their use. ${ }^{31}$

To mitigate these symptoms, outpatient programs have used $\mathrm{a}_{2}$-agonists (clonidine, dexmedetomidine), agonist-antagonists (buprenorphine), benzodiazepines (diazepam, midazolam), and antidepressants (trazadone) to assist in the detoxification of the patients. This takes place over a week, and patients are then converted to the use of a maintenance antagonist. ${ }^{32,33}$ More recently, ultrarapid opiate detoxification (UROD; also known as rapid opiate withdrawal or detoxification) has been developed as a means of avoiding the physical symptoms of withdrawal from opiates by using general anesthesia. ${ }^{34}$ The method was first described by Loimer and colleagues in $1990 . .^{35}$

The technique of rapid detoxification is designed to shorten the detoxification process to a four- to sixhour period by precipitating withdrawal following the administration of large doses of opioid antagonists. ${ }^{36-38}$ Rasmussen et al. demonstrated in morphine addicted rats that electrophysiological, biochemical, and behavioural parameters of opioid withdrawal involving the locus ceruleus, peaked and recovered within six hours of high-dose opioid antagonist administration. ${ }^{39}$

A variety of techniques have recently appeared in the literature. ${ }^{33,40,41}$ These techniques vary with respect to type of anesthesia, pharmacological agents used, and the hospital setting where the procedure takes place. No one particular technique has been shown superior thus far. A three-year study from the National Institute of Drug Abuse comparing rapid detoxification with two forms of slow detoxification began in September, 2000. In one study of 20 patients, only deep sedation with midazolam was used. There was a high incidence of vomiting, which greatly increased the risk of aspiration. Currently, the most popular technique is general anesthesia using a total $i$ p technique with propofol. The method we would like to present has been described by Gevirtz et al. and Cucchia et al. ${ }^{42,43}$ 


\section{Ultrarapid detoxification}

Patient selection

Proper patient selection is essential. The patient must meet the Diagnostic and Statistical Manual IV criteria for addiction, confirmed by positive laboratory testing (positive urine, hair, or blood test). A drug history is obtained, and the drug of abuse is identified. While co-addiction is a relative contraindication, acute cocaine intoxication may add additional risk to the procedure due to the increased incidence of arrhythmias and is an absolute contraindication. ${ }^{44}$ Similarly, patients who have a positive drug screen for cocaine just prior to the procedure should not undergo the procedure. The patient's detoxification history should be obtained in addition to psychiatric history. A psychologist or psychiatrist must rule out active psychosis or suicidal ideation. Laboratory testing should include complete blood count, electrolytes, glucose, and renal and liver function tests. Since many opioid preparations contain adjuvants such as acetaminophen or ibuprofen, renal or liver dysfunction may be present. Urine toxicology for opioids, benzodiazepines, phencyclidine, cocaine, amphetamines, cannabinoids, barbiturates, propoxyphene, tricyclics and alcohol must be included. Results of these tests can be matched with the patient's drug history and give an indication of the patient's credibility.

Patients with chronic pain syndromes requiring opioid medication are not good candidates unless pain can be controlled with alternative methods. It is essential that a follow-up program be in place as a condition of the procedure. Details pertinent to the rapid detoxification procedure must be explained to the patient. In addition, a supportive home environment must exist and caregivers must be given postoperative instructions. Due to the high prevalence of co-existing disease, a thorough history and physical examination must be performed. Electrocardiogram (EKG) and chest $x$-ray are obtained to assist in the cardiopulmonary evaluation. Laboratory tests for immunodeficiency syndromes, hepatitis A, B, C, and D and syphilis testing may be useful in this high-risk population; however, the presence of these infections is not necessarily a contraindication to the procedure. In general, patients with uncontrolled medical problems (ASA physical status III or more) are not good candidates. Pregnancy is an absolute contraindication and a negative pregnancy test should be documented as appropriate.

\section{Preoperative preparation}

While withdrawal from methadone may last up to ten days, withdrawal from Dilaudid ${ }^{\circledR}$ (hydromorphone) is usually complete within six hours. ${ }^{40}$ Because it is not reasonable to anesthetize a patient for ten days, the patient's addiction should be transferred from their drug of choice to a short acting opioid such as morphine or hydromorphone. The night prior to the procedure, all drug intake should cease and, the patient must be $n p o$ after midnight. A clonidine patch $0.2 \mathrm{mg}$ should be applied $12 \mathrm{hr}$ before the procedure. An enema the night before surgery may be useful since these patients have hypermotility of the gastrointestinal tract resulting in severe diarrhea during the rapid detoxification procedure.

The optimal setting for this procedure is the intensive care unit, where expertise and assistance is readily available and monitoring is adequate. The recovery room or another monitored setting is acceptable provided emergency equipment and medications are available. Prior to the procedure, the patient should have aspiration prophylaxis with an $\mathrm{H}_{2}$ receptor blocker or a proton pump inhibitor. Antidopaminergic agents like metoclopramide should be avoided, as the effects on the central nervous system may exacerbate the symptoms of withdrawal. ${ }^{45}$ Monitors should include EKG, pulse oximetry, and noninvasive blood pressure measurement. More invasive types of hemodynamic monitoring are usually not necessary. Further monitoring should include core temperature, urine output, and if possible, the bispectral index (BIS), although the median electroencephalogram (EEG) frequency may be a more sensitive indicator of sympathetic activation with opioid reversal. ${ }^{46}$ Minute ventilation, peak inspiratory pressures, respiratory rate, and capnography should also be monitored.

\section{Induction of anesthesia}

Once the patient is monitored, clonidine 0.1 to 0.2 $\mathrm{mg}$, preferably transdermally, should be given to a maximum of 0.5 to $0.6 \mathrm{mg}$. Sympathetic activity will be adequately suppressed typically if the heart rate is below 60 beats. $\mathrm{min}^{-1}$ and systolic blood pressure is below $100 \mathrm{mmHg}$. An anticholinergic can be given to decrease hypersecretion. A rapid sequence induction is performed because these patients typically have delayed gastric emptying. ${ }^{47}$ Anesthesia is induced with propofol, but alternative induction agents like barbiturates are acceptable.

Anesthesia is maintained with propofol, methohexital, or inhalational agents. Octeotride, a somatostatin analogue, has been particularly useful in controlling intestinal hypersecretion and motility. ${ }^{48}$ In addition ondansetron, a serotonin receptor antagonist, is administered to attenuate associated nausea and vomiting. ${ }^{49}$ Minute ventilation is a sensitive indicator of withdrawal and may increase twofold during with- 
drawal. Patients are paralyzed with succinylcholine (unless contraindicated) and intubated. Upon recovery from succinylcholine, the patients are allowed to spontaneously breathe room air supplemented with oxygen. Patients are not routinely paralyzed for the duration of the procedure, due to the need to observe signs of withdrawal. However, if necessary, a long-acting nondepolarizing muscle relaxant can be used in conjunction with mechanical ventilation. A urinary catheter and an orogastric or nasogastric tube should be inserted.

\section{Initiation of opioid withdrawal}

Withdrawal is precipitated by the $i v$ injection of high dose naloxone. Any antagonist (naloxone, naltrexone or nalmefene) may be used for detoxification. All antagonists have high binding coefficients compared to the agonists, (naltrexone binds at the receptor 34 times more than morphine). ${ }^{50}$ Naltrexone, administered via a nasogastric tube, has been used safely and effectively in large numbers of patients. However, uptake from the gastrointestinal tract is highly variable and is therefore unreliable. Insufficient levels of plasma naltrexone were found in four out of ten patients receiving up to $50 \mathrm{mg}$ of naltrexone by mouth. ${ }^{44}$ One described technique involves nalmefene, up to $4 \mathrm{mg}$, infused over two hours. ${ }^{37}$ Since iv naloxone is relatively inexpensive and provides reliable and predictable responses, this is the preferred antagonist by most centres. ${ }^{37,38,40}$ The main difference in these three antagonists is duration of action. Naloxone has a halflife of one to two hours, while naltrexone and nalmefene have half-lives of the order of ten hours. Questions have arisen regarding the risk of pulmonary edema when using naloxone in opiate dependent patients. The presumed cause of the edema is an adrenergic crisis with a large increase in catecholamines, an effect documented in a study by Kienbaum et al. ${ }^{51}$ Clonidine blunts the response to this increase in plasma catecholamines and prevents any significant cardiovascular changes. ${ }^{24}$

A test dose of naloxone, $1 \mathrm{mg}$ intravenously, is administered. If the patient does not respond with a significant increase in heart rate and blood pressure, it is assumed that the sympathetic responses are sufficiently blunted. A dose of naloxone, 20 to $30 \mathrm{mg}$ over 10 to $15 \mathrm{~min}$, is given. This is followed by an infusion of naloxone at a rate of $1 \mathrm{mg} \cdot \mathrm{hr}^{-1}$. The depth of anesthesia is reduced to a BIS reading of approximately $60 \%$, and the patient is observed for signs of withdrawal. Signs of withdrawal include: hypertension (systolic pressure $>140 \mathrm{mmHg}$ ), tachycardia (> 90 $\min ^{-1}$ ), tachypnea (respiratory rate $>20$ ), mydriasis, lacrimation, rhinorrhea, diaphoresis, piloerection, yawning, myoclonus, hyperthermia, minute ventilation, Q-Q variability, and median EEG frequency. ${ }^{52-54}$

Excessive withdrawal responses can be controlled with appropriate drugs. If clonidine is not effective in the control of hemodynamics, beta-blockers, such as labetalol or esmolol may be indicated. Severe diarrhea is treated with octeotride. Full blown withdrawal symptoms with high blood pressures, excessive myoclonus or seizure like behaviour can be controlled with propofol or a barbiturate. ${ }^{51}$ Since fluid loss via the gastrointestinal tract can be considerable, adequate fluid replacement may be necessary. ${ }^{55}$

A reliable method in assessing the adequacy of withdrawal is the iv reinjection of high dose naloxone (20-30 mg). If the patient does not show exacerbation of the signs of withdrawal, detoxification is considered adequate. Absence of response to a naloxone challenge may require six hours of general anesthesia with injection of high dose naloxone at repeated intervals.

In preparation for the patient's emergence from anesthesia, the bladder catheter is removed, the stomach is suctioned, and the gastric tube removed. When the patient is awake, responsive, and protective reflexes are present, the trachea is extubated. When the patient is stable and well oriented, a subjective opioid withdrawal scale (SOWS) is determined. ${ }^{56}$ This scale ranges from 0 to 60 , is made up of 15 different sections, each being scored from 0 (not at all) to 4 (extremely.) Examples of these sections include nervousness, bone pain, nausea, craving for opioid, and restlessness. The SOWS should be less than 20 . If this is not the case, reintubation should be considered and additional challenges with high dose opioid antagonist administered. If detoxification is adequate (SOWS < 20 ), the patient is monitored in the intensive care unit, recovery room or any adequately monitored setting. Monitoring should include signs of withdrawal. Residual effects of withdrawal should be treated symptomatically. In the hours following UROD, naltrexone $50 \mathrm{mg}$ po is given. Daily naltrexone $50 \mathrm{mg}$ po for at least six months is part of the detoxification process. When the patient has been monitored for $24 \mathrm{hr}$, symptoms of withdrawal are within acceptable limits, and the patient meets the usual criteria for discharge from the recovery room of an outpatient facility, the patient may be released.

Several methods have been used to measure the adequacy of withdrawal. A major decrease in signs of withdrawal in response to the opioid antagonist is critical. A decrease of $20 \%$ of the minute ventilation below the maximum minute ventilation, a decrease in Q-Q variability on the EKG and normalization of 
EEG have been used to measure the adequacy of withdrawal. ${ }^{44,50}$

\section{Post UROD problems}

Detoxification and withdrawal are rarely complete following UROD. Residual withdrawal symptoms may include: drug craving, sympathetic hyperactivity, muscle pain, bone pain, nausea, vomiting, diarrhea, and insomnia. A syndrome of protracted abstinence is described lasting three to ten weeks and characterized by restlessness, irritability, insomnia and hypertension. After detoxification, treatment is largely symptomatic.

Naltrexone reduces feelings of craving. The neuropharmacology is unclear but reproducibility is marked and suggests that long-term therapy is indicated. ${ }^{6}$ Patients undergoing long-term therapy (more than three months) with naltrexone can become sensitized to the effects of opiate drugs. Patients "reset" to the effects of opiates. Thus, if a patient is not aware of this "biological reset", he/she could theoretically self-administer equivalent opiates to those commonly used prior to the procedure and suffer opiate overdose. However, this is only possible if the patient stops taking the antagonist.

The risks of taking naltrexone are relatively few. Naltrexone therapy, at doses five times greater than those prescribed to prevent opiate abuse relapse, has been found to produce changes in laboratory tests that suggest mild liver dysfunction. These changes were completely reversed when the administration of these high doses was stopped. ${ }^{57}$ Similar changes in these laboratory tests were not seen for patients who took naltrexone chronically at doses used to prevent relapse (up to $50 \mathrm{mg} \cdot \mathrm{day}^{-1}$ ). However, patients who have a history of preexisting liver dysfunction should begin naltrexone maintenance therapy only under careful supervision of a physician and weekly monitoring of liver function tests. At high doses in pregnant laboratory animals, naltrexone is harmful to developing fetuses. ${ }^{58}$ Naltrexone is contraindicated in pregnant and lactating women because it is excreted in breast milk. ${ }^{59}$

In general, the patient should be kept warm and be allowed frequent warm showers. Clonidine reduces sympathetic hyperactivity and should be continued through the protracted abstinence syndrome. Irritability may be managed with psychotherapy, benzodiazepines, and antidepressants.

Immediately following detoxification, patients may feel exhausted and weak. Other complications, related mainly to the gastrointestinal tract, follow quickly and may last for days. Slight variations in hemodynamic status or other signs of withdrawal may be treated with small amounts of medications including midazolam, ketorolac or clonidine. Oral naltrexone maintenance may be started as soon as the patient is awake, although administration may be delayed because of vomiting. ${ }^{37}$ Many patients are able to return to work in a few days.

Emesis is a prominent component of the withdrawal syndrome. The use of prophylactic agents such as ondansetron and ranitidine are necessary. In fact, complications as serious as Mallory-Weiss tears have been reported. ${ }^{60}$

Octreotide is used to control post detoxification diarrhea. Loperamide, a piperidine derivative, has also been used in the past since it slows gastrointestinal motility through a direct effect on the nerve endings and the intramural ganglia of the intestinal wall. ${ }^{61}$

The number one reason for failure of detoxification in the first two weeks postprocedure is insomnia. In treating insomnia, it is important to realize that narcotics disrupt the normal sleep wake cycle, and many addicts require narcotics to sleep. The long-term disruption of normal sleep wake cycle cannot be corrected rapidly. Normal amounts of melatonin release and the normal circadian rhythm typically take at least a week to become reestablished. ${ }^{62}$

Orally administered melatonin $(3 \mathrm{mg})$, benzodiazepines, and antihistamines can all be beneficial. ${ }^{63}$ Hypnosis and alternative relaxation techniques can also be used. Self-hypnosis can be taught fairly easily to addicts. It is important to not start prescribing large amounts of benzodiazepines since these drugs also have addictive potential and do not lead to a restorative sleep pattern. As part of the pre-procedure informed consent, the patient must be made aware of the potential for insomnia.

Muscle cramps and low back pain complaints are treated with non-steroidal anti-inflammatory drugs. Newer cyclooxygenase 2 inhibitors are desirable because they have few or no gastrointestinal side effects. ${ }^{64}$

In a poster presentation analysis of "Intensive Narcotic Detoxification", of 162 patients, Simon and Findlay, described two other complications. ${ }^{\mathrm{A}}$ One patient sustained a small gastric hemorrhage due to a gastric ulcer. The patient was successfully treated with $\mathrm{H}_{2}$ blockers and the authors concluded that her epigastric pain had been masked previously by heroin. Another patient described vague neurologic changes including speech difficulties and peripheral numbness.

\footnotetext{
A Simon D, Findlay $R$. Intensive narcotic detoxification (SM) at Nutmeg Intensive Rehabilitation Center. American Society of Addiction Medicine Annual Meeting. Poster presentation, April 1998.
} 
Resolution occurred over several weeks. The symptoms were attributed to an idiosyncratic drug reaction. No other morbidities occurred in this series although two patients died of drug overdose months after the procedure.

\section{Conclusion}

There is continuing debate on new treatment approaches beyond methadone for opiate addiction. UROD withdrawal from opiates is associated with few adverse events and is a relatively comfortable undertaking. The future may include making the procedure available to a larger patient population.

\section{References}

1 http://www.drugabuse.gov/Infofax/nationtrends.html.

2 Zwillich T. Prescription drug abuse said to be on the rise. Reuters 2001; April 10.

3 http://www.nlm.nih.gov/medlineplus/news/fullstory_1171.html.

4 www.drugabuse.gov/ResearchReports/Heroin/heroin $2 . h t m l \# s c o p e$

5 Stafford K, Gomes AB, Shen J, Yoburn BC. mu-opioid receptor downregulation contributes to opioid tolerance in vivo. Pharmacol Biochem Behav 2001; 69: 233-7.

6 Gold MS. Opiate addiction and locus coeruleus. The clinical utility of clonidine, naltrexone, methadone, and buprenorphine. Psychiatr Clin North Am 1993; 16: 61-73.

7 www.drugabuse.gov/Infofax/heroin.html.

8 Koob GF. Neurobiology of addiction. Toward the development of new therapies. Ann N Y Acad Sci 2000; 909: 170-85.

9 Spanagel R. Is there a pharmacological basis for therapy with rapid opioid detoxification? Lancet 1999; 354: 2017-8.

10 Roizen MF. How does $\mu$-opioid receptor blockade work in addicted patients? Anesthesiology 1998; 88: 1142-3.

11 Bovill JG. Opioid detoxification under anaesthesia. Eur J Anaesthesiol 2000; 17: 657-61.

12 Nestler EJ. Under siege: the brain on opiates. Neuron 1996; 16: 897-900.

13 Blendy JA, Maldonado R. Genetic analysis of drug addiction: the role of cAMP response element binding protein. J Mol Med 1998; 76: 104-10.

14 Maldonado R, Blendy JA, Tzavara E, et al. Reduction of morphine abstinence in mice with a mutation in the gene encoding CREB. Science 1996; 273: 657-9.

15 Maldonado R, Stinus L, Koob GF, et al. Neurobiological Mechanisms of Opiate Withdrawal. New York: USA Springer; 1996.
16 Mattick RP, Hall $W$. Are detoxification programmes effective? Lancet 1996; 347: 97-100.

17 Jasinski DR. Tolerance and dependence to opiates. Acta Anaesthesiol Scand 1997; 41: 184-6.

18 Kleber HD, Topazian M, Gaspari J, Riordan CE, Kosten T. Clonidine and naltrexone in the outpatient treatment of heroin withdrawal. Am J Drug Alcohol Abuse 1987; 13: 4-17.

19 O'Brien CP, McLellan AT. Myths about the treatment of addiction. Lancet 1996; 347: 237-40.

20 Broers B, Giner F, Dumont P, Mino A. Inpatient opiate detoxification in Geneva: follow-up at 1 and 6 months. Drug Alcohol Depend 2000; 58: 85-92.

21 Fudula PJ, Jaffe JH, Dax EM, Johnson RE. Use of buprenorphine in the treatment of opiate addiction. II. Physiologic and behavioral effects of daily and alternate-day administration and abrupt withdrawal. Clin Pharmacol Ther 1990; 47: 525-34.

22 Alling FA, Johnson BD, Elmoghazy E. Cranial electrostimulation (CES) use in the detoxification of opiatedependent patients. J Subst Abuse Treat 1990; 7: 173-80.

23 Poshychinda $V$. Thailand: treatment at the Tam Kraborg Temple. In: Edwards G, Arif A (Eds.). Drug Problems in the Sociocultural Context: a Basis for Policies and Program Planning. Geneva: World Health Organization; 1980: 121-5.

24 Kienbaum P, Scherbaum N, Thurauf N, Michel MC, Gastpar M, Peters J. Acute detoxification of opioidaddicted patients with naloxone during propofol or methohexital anesthesia: a comparison of withdrawal symptoms, neuroendocrine, metabolic, and cardiovascular patterns. Crit Care Med 2000; 28: 969-76.

25 Christie MJ, Williams JT, Osborne PB, Bellchambers CE. Where is the locus in opioid withdrawal? Trends Pharmacol Sci 1997; 18: 134-40.

26 Keinbaum P, Thurauf N, Michel MC, Scherbaum N, Gastpar M, Peters J. Profound increase in epinephrine concentration in plasma and cardiovascular stimulation after $\mu$-opioid receptor blockade in opioid addicted patients during barbiturate-induced anesthesia for acute detoxification. Anesthesiology 1998; 88: 1154-61.

27 Langer SZ. Presynaptic regulation of release of catecholamines. Pharmacol Rev 1981; 32: 337-62.

28 Gold MS, Redmond DE Jr, Kleber HD. Noradrenergic hyperactivity in opiate withdrawal supported clonidine reversal of opiate withdrawal. Am J Psychiatry 1979; 136: 100-2.

29 Diaz A, Pazos A, Florez J, Ayesta FJ, Santana V, Hurle $M A$. Regulation of mu-opioid receptors, G-proteincoupled receptor kinases and beta-arrestin 2 in the rat brain after chronic opioid receptor antagonism. Neuroscience 2002; 112: 345-53. 
30 Charney DS, Heninger GR, Kleber D. The combined use of clonidine and naltrexone as a rapid, safe, and effective treatment of abrupt withdrawal from methadone. Am J Psychiatry 1986; 143: 831-7.

31 Ward J, Hall W, Mattick RP. Role of maintenance treatment in opioid dependence. Lancet 1999; 353: 221-6.

32 Farrel M. Opioid withdrawal. Addiction 1994; 89: 1471-7.

33 Senft $R A$. Experience with clonidine-naltrexone for rapid opiate detoxification. J Subst Abuse Treat 1991; 8: 257-9.

34 Resnick RB, Kestenbaum RS, Washton A. Poole D. Naloxone-precipitated withdrawal: a method for rapid induction onto naltrexone. Clin Pharmacol Ther 1977; 21: 409-13.

35 Loimer N, Schmid R, Lenz K, Presslich O, Grunberger J. Acute blocking of naloxone-precipitated opiate withdrawal symptoms by methohexitone. Br J Psychiatry 1990; 157: 748-52.

36 Presslich $O$, Loimer $N$. Opiate detoxification under general anesthesia by large doses of naloxone. J Toxicol Clin Toxicol 1989; 27: 263-70.

37 Simon DL. Rapid opioid detoxification using opioid antagonists: history, theory and the state of the art. J Addict Dis 1997; 16: 103-22.

38 Legarda JJ, Gossop M. A 24-h inpatient detoxification treatment for heroin addicts: a preliminary investigation. Drug Alcohol Depend 1994; 35: 91-3.

39 Rasmussen K, Beitner-Johnson DB, Krystal JH, Aghajanian GK, Nestler EJ. Opiate withdrawal and the rat locus coeruleus: behavioral, electrophysiological, and biochemical correlates. J Neurosci 1990; 10: 2308-17.

40 Gold CG, Cullen DJ, Gonzales S, Houtmeyers D, Dwyer $M J$. Rapid opioid detoxification during general anesthesia. Anesthesiology 1999; 91: 1639-47.

41 Lorenzi P, Marsili M, Boncinelli S, et al. Searching for a general anaesthesia protocol for rapid detoxification from opioids. Eur J Anaesthesiol 1999; 16: 719-27.

42 Cucchia AT, Monnat M, Spagnoli J, Ferrero F, Bertschy $G$. Ultra-rapid opiate detoxification using deep sedation with midazolam: short and long-term results. Drug Alcohol Depend 1998; 52: 243-50.

43 Gevirtz C, Frost E. Ultra rapid opiate detoxification current concepts. Curr Opin Clin Exp Res 2000; 2: 151-68.

44 McDonald T, Berkowitz R, Hoffman WE. Plasma naltrexone during opioid detoxification. J Addict Dis 2000: 19: 59-64.

45 Walters CL, Aston-Jones G, Druban JP. Expression of fos-related antigens in the nucleus accumbens during opiate withdrawal and their attenuation by a D2 dopamine receptor agonist. Neuropsychopharmacology 2000; 23: 307-15.

46 McDonald T, Berkowitz R, Hoffman WE. Median EEG frequency is more sensitive to increases in sympathetic activity than bispectral index. J Neurosurg Anesthesiol 1999; 11: 255-9.

47 Tweedle D, Nightingale P. Anesthesia and gastrointestinal surgery. Acta Chir Scand Suppl 1989; 550: 131-9.

48 Brewer C. Ultra rapid, antagonist-precipitated opiate detoxification under general anaesthesia or sedation. Addiction Biol 1997; 2: 291-302.

49 Wilde MI, Markham A. Ondansetron. A review of its pharmacology and preliminary clinical findings in novel applications. Drugs 1996; 52: 773-94.

50 Madsen BW, Albuquerque EX. The narcotic antagonist naltrexone has a biphasic effect on the nicotinic acetylcholine receptor. FEBS Lett 1985; 182: 20-4.

51 Kienbaum P, Thuauf N, Michel MC, Scherbaum N, Gastpar M, Peters J. Profound increase in epinephrine concentration in plasma and cardiovascular stimulation after mu-opioid receptor blockade in opioid-addicted patients during barbiturate-induced anesthesia for acute detoxification. Anesthesiology 1998; 1154-161.

52 Hoffman WE, Berkowitz R, McDonald T, Hass F. Ultra-rapid opioid detoxification increases spontaneous ventilation. J Clin Anesth 1998; 10: 372-6.

53 McDonald T, Hoffman WE, Berkowitz R, Cunningham $F$, Cooke B. Heart rate variability and plasma catecholamines in patients during opioid detoxification. J Neurosurg Anesthesiol 1999; 11: 195-9.

54 Manilli P, De Risio S, Pozzi G, Janiri L, De Giacomo $M$. Serendipitous rapid detoxification from opiates: the importance of time-dependent processes. Addiction 1999; 94: 589-91.

55 Ronnback L, Eriksson PS, Zeuchner J, Rosengren L, Wronski A. Aspects of abstinence after morphine ingestion. Pharmacol Biochem Behav 1987; 28: 87-93.

56 Handelsman L, Cochrane KJ, Aronson MJ, Ness R, Rubinstein KJ, Kanof PD. Two new rating scales for opiate withdrawal. Am J Drug Alcohol Abuse 1987; 13: 293-308.

57 Kosten TR, Kreek MJ, Ragunath J, Kleber HD. Cortisol levels during chronic naltrexone maintenance treatment in ex-opiate addicts. Biol Psychiatry 1986; 21: 217-20.

58 Dunlap CE 3rd, Valego NK, Rose JC. Comparison of high-dose opioid antagonist effects on ovine fetal cardiovascular function Dev Pharmacol Ther 1989; 13: 28-37.

59 Jepsen $P W$. Naltrexone. An opioid antagonist to support the drug-free state in previous opioid addicts having stopped the habit (Danish). Ugeskr Laeger 1990; 152: 2546-9.

60 Chanmugam AS, Hengeller M, Ezenkwele U. 
Development of rhabdomyolysis after rapid opioid detoxification with subcutaneous naltrexone maintenance therapy. Acad Emerg Med 2000; 7: 303-5.

61 Burleigh DE. Opioid and non-opioid actions of loperamide on cholinergic nerve function in human isolated colon. Eur J Pharmacol 1988; 152: 39-46.

62 Staedt J, Wassmuth F, Stoppe G, et al. Effects of chronic treatment with methadone and naltrexone on sleep in addicts. Eur Arch Psychiatry Clin Neurosci 1996; 246: 305-9.

63 Millman RP. Therapy of insomnia. Med Health R I 2002; 85: 99-100.

64 Shah AA, Thjodleifsson B, Murray FE, et al. Selective inhibition of COX-2 in humans is associated with less gastrointestinal injury: a comparison of nimesulide and naproxen. Gut 2001; 48: 339-46.

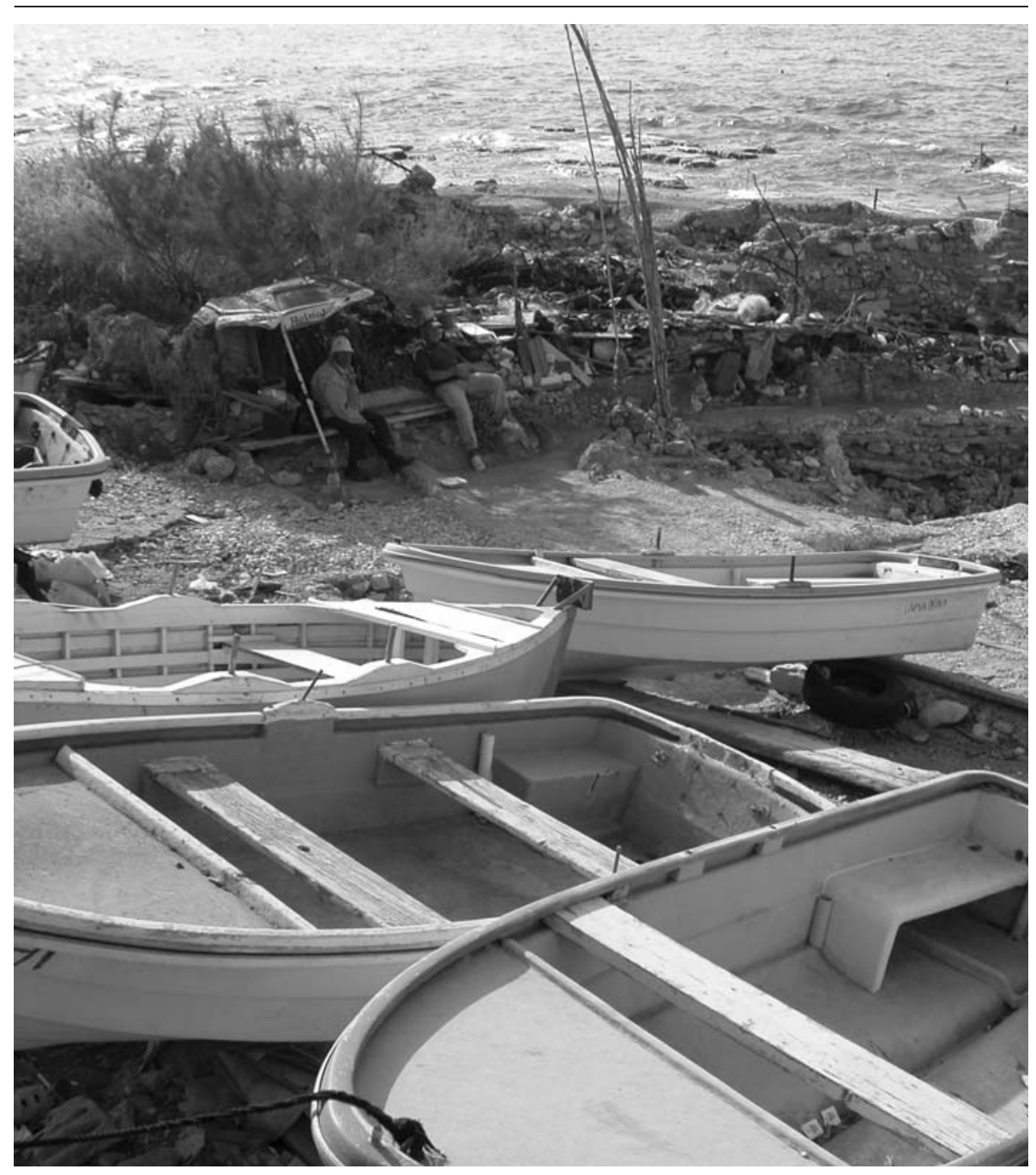

Beirut - Lebanon 